\title{
Flexible Delivery Approaches to Couple Relationship Education: Predictors of Initial Engagement and Retention of Couples
}

\author{
Dean M. Busby \\ Brigham Young University - Provo, dean_busby@byu.edu \\ Jeffry H. Larson \\ Brigham Young University - Provo \\ Thomas B. Holman \\ Brigham Young University - Provo \\ W. Kim Halford \\ University of Queensland \\ Follow this and additional works at: https://scholarsarchive.byu.edu/facpub \\ Part of the Other Social and Behavioral Sciences Commons
}

\section{Original Publication Citation}

Busby, D. M., Larson, J. F., Holman, T. B., \& Halford, W. K. (2015). Flexible delivery approaches to couple relationship education: Predictors of initial engagement and retention of couples. Journal of Child and Family Studies, 24, 3018-3029.

\section{BYU ScholarsArchive Citation}

Busby, Dean M.; Larson, Jeffry H.; Holman, Thomas B.; and Halford, W. Kim, "Flexible Delivery Approaches to Couple Relationship Education: Predictors of Initial Engagement and Retention of Couples" (2015). Faculty Publications. 4623.

https://scholarsarchive.byu.edu/facpub/4623

This Peer-Reviewed Article is brought to you for free and open access by BYU ScholarsArchive. It has been accepted for inclusion in Faculty Publications by an authorized administrator of BYU ScholarsArchive. For more information, please contact ellen_amatangelo@byu.edu. 


\title{
Flexible Delivery Approaches to Couple Relationship Education: Predictors of Initial Engagement and Retention of Couples
}

\author{
Dean M. Busby $\cdot$ Jeffry H. Larson • \\ Thomas B. Holman • W. Kim Halford
}

Published online: 4 January 2015

(c) Springer Science+Business Media New York 2015

\begin{abstract}
In this study, using a national recruitment strategy, we tested the different factors that influence retention in four different types of relationship education (RE), a self-directed book, assessment and feedback, and a six session Couple CARE program delivered by email or by phone. Of all the factors considered, required program effort, highly valuing marriage, religiosity, education, and step-family status were able to predict with seventy percent accuracy which couples would complete or not complete their RE experience. Program effort was substantially better at predicting retention than all other variables. Retention was high in the book and assessment conditions but was much lower in the two Couple CARE conditions where more effort and time was required. Initial engagement was higher in the email based Couple CARE condition but overall retention was higher in the phone based condition. Important implications for current and future RE efforts are proposed.
\end{abstract}

Keywords Couple relationship education - Flexible delivery $\cdot$ Retention

\section{Introduction}

Couple relationship education (RE) is the provision of structured education intended to promote healthy couple

D. M. Busby $(\bowtie) \cdot$ J. H. Larson · T. B. Holman

School of Family Life, Brigham Young University, Provo, UT 84602, USA

e-mail: dean_busby@byu.edu

W. K. Halford

University of Queensland, St Lucia, Brisbane, QLD, Australia relationships, and prevent future relationship distress (Halford et al. 2008). While there is considerable evidence that attending face-to-face RE helps at least some couples communicate more positively and sustain relationship satisfaction (Halford and Bodenmann 2013), the majority of couples never attend RE programs. Flexible delivery RE, in which couples can participate in RE without having to attend face-to-face sessions, has been suggested as a way of extending the reach of RE and preliminary data suggest it can enhance couple relationships (McAllister et al. 2013).

Evidence-based RE draws upon the substantial research on what influences couple relationship satisfaction and stability, and uses an approach to RE that has been evaluated in well-designed research trials (Halford 2011; Halford et al. 2008). The most widely researched RE is curriculum based, which is typically delivered in face-toface groups of couples, and consists of 9-20 h of curriculum that introduces key relationship knowledge (e.g., the importance of commitment, developing shared realistic relationship expectations) and skills (e.g., couple communication, coping) (Markman and Rhoades 2012).

A second widely used approach to RE is inventory-based assessments that are used to give couples detailed feedback about relationship strengths and weaknesses (Larson et al. 2002), based on the assumption that such feedback can guide couples to strengthen their relationships. Sometimes inventory assessment constitute the entire process of RE, and sometimes inventories are used as part of curriculum based RE (Larson et al. 2002). While inventories are widely used and have an empirical basis to their development, there is only one randomized controlled trial of assessment and feedback alone, which found that RELATE assessment and feedback provided to engaged or dating couples increased short-term relationship satisfaction (Larson et al. 2007). 
Although RE is conceptually distinct from couple therapy, a substantial proportion of couples presenting for RE have at least mild relationship distress (de Maria 2005). For these distressed couples RE might have similar benefits as couple therapy in producing an increase in relationship satisfaction immediately after RE. However, universal and selective offerings of RE typically attract a majority of couples who are currently highly satisfied, and there might be little immediate scope for increases in satisfaction. In universal and selective offerings of RE the potential benefit of RE is in helping couples to sustain high satisfaction.

What are the effects of relationship education? A metaanalysis of 117 studies of curriculum based RE reported medium effect size improvements in couple communication, $d=.44$, and small increases in relationship satisfaction, $d=.36$, immediately after RE, which were maintained through to 6 months follow-up (Hawkins et al. 2008). Programs with moderate dosage $(9-20 \mathrm{~h})$ had substantially larger effect sizes than low dose programs (1-8 h). As very few of the RE studies included in that meta-analysis had follow-up assessments of more than 6 months, Hawkins et al. could not reach conclusions on the long-term effects of RE.

Halford and Bodenmann (2013) reviewed 17 randomized controlled trials of curriculum based RE that evaluated the effects of RE for 12 months or more. Thirteen of the 17 trials were with samples of couples who were at high risk for future relationship satisfaction decline, either because of life events (e.g., about to have their first child, which is known to be associated with decline of relationship satisfaction) or couple characteristics (e.g., a large proportion of couples with histories of parental divorce or violence in the family of origin). In 11 of these 13 trials with high-risk couples RE produced significant enhancement of couple relationship satisfaction at follow ups ranging from 1 to 5 years (Halford and Bodenmann 2013). Two trials were with samples of couples in which the mean relationship satisfaction was somewhat low, and might be regarded as early intervention for mild relationship distress. Both these trials found RE enhanced relationship satisfaction. Only two studies were universal trials that were offered to couples who predominantly were low risk. One study found RE enhanced relationship satisfaction and one trial did not. Halford and Bodenmann concluded there is evidence of a selective benefit from RE in helping some high-risk couples sustain relationship satisfaction, but that there was not clear evidence of a universal benefit of RE.

What is the reach of relationship education? Historically, RE evolved from brief premarital counseling offered by religious marriage celebrants (Hunt et al. 1998), and premarital RE offered by religious organizations continues to be the most common means of accessing RE (Halford and Simons 2005; Stanley et al. 2006). The proportion of couples attending premarital RE has increased more than tenfold since the 1950s (Doss et al. 2009; Stanley et al. 2006). However, still only about 30-35\% of marrying couples attend RE (Halford et al. 2006; Stanley et al. 2006; Sullivan and Bradbury 1997). Furthermore, there is some evidence that there is an under-representation of high-risk couples in those who attend current pre-marital RE offerings. By definition premarital $\mathrm{RE}$ fails to reach the considerable and growing proportion of couples who cohabit rather than marry, and cohabiting couples are known to have higher risk for relationship dissatisfaction and separation than marrying couples (Weston et al. 2012). Second marriage couples are at higher risk of relationship distress than first marriage couples and are substantially less likely to attend RE than first marriage couples (Doss et al. 2009; Halford et al. 2006).

The modest reach of premarital RE to high-risk couples highlights the need to recruit couples to RE at a variety of times in couples' lives. Petch et al. (2012) recruited couples for RE who were expecting their first child through antenatal classes and found they could attract high-risk couples (e.g., couples who were cohabiting, had unplanned pregnancy and had a history of low level inter-partner violence), although there was an under-representation of minority couples and couples with low education. The Building Strong Families (BSF) project is a very large ( $n=6,212$ couples) eight site evaluation of several different RE programs specifically targeted to unmarried couples expecting a child together (Wood et al. 2012). While large numbers of high risk couples were attracted to register for RE programs, attrition and low attendance was a substantial problem across most sites, with $45 \%$ of couples never attending a single RE session. This low attendance occurred despite couples being offered free meals and on-site child care, transportation assistance, and even at some sites cash incentives, gift cards, or baby products to promote attendance.

What influences attendance or participation in RE? There have been a number of studies that have tested whether attractants and barriers predict RE attendance. There is a consistent finding that placing a high value on marriage in general, and having a strong commitment to one's own relationship, each predict RE attendance (Blair and Cordova 2009; Duncan et al. 2007; Silliman and Schumm 1995; Sullivan et al. 2004). Intent to attend RE is predicted by people believing they are at risk for developing relationship problems Sullivan et al. (2004), or that they currently have problems in their relationship (Duncan et al. 2009; Halford and Simons 2005), presumably as they perceive RE as a means of addressing these problems. The attendance of RE by those couples who currently have problems is a two-edged sword. On the one hand, people with some difficulties are getting help. On the other hand, despite the efforts of many RE advocates to market RE as 
prevention and enrichment, many currently satisfied couples who might benefit from RE do not attend as they report they see RE as being only for couples with problems (Halford and Simons 2005; Roberts and Morris 1998).

The most consistently reported barrier to RE attendance is the perceived inconvenience of getting to RE, and the time taken attending face-to-face sessions (Halford and Simons 2005; Roberts and Morris 1998; Sullivan et al. 2004). Young people report that they would be more likely to attend RE that was brief and low cost (Silliman and Schumm 1995; Silliman and Schumm 2004). Moreover, perceived inconvenience is a particularly strong barrier to $\mathrm{RE}$ attendance among couples who perceive little potential benefit for them in RE attendance (Sullivan et al. 2004).

Another barrier to RE attendance is a perception among those couples who do not attend RE that RE is religious and socially conservative (Halford and Simons 2005). Religious couples are more likely to attend RE than other couples (Duncan et al. 2007; Halford et al. 2006), which presumably reflects that RE historically has been championed and offered by religious organizations, and that religious couples are more likely to access such services. While providing RE to religious couples is a good thing, higher risk for relationship problems is predicted by low religiosity (Sullivan 2001). Attracting less religious couples to RE is a significant challenge that needs to be addressed.

One of the ways to reduce barriers to RE attendance could be delivering the content in more flexible formats. Most RE programs are delivered in face-to-face sessions, often in small groups of couples (Halford 2011). However, a number of evidence-based RE programs have been offered in flexible delivery mode (e.g., Braithwaite and Fincham 2009; Halford et al. 2010). Flexible delivery refers to the use of self-directed learning materials (e.g. online resources, DVD) where couples can complete the program in their own time, and without attending face-toface sessions. Flexible delivery has the potential to enhance the reach of RE as couples are more likely to read books (Doss et al. 2009) or access a website (Casey and Halford 2010) on relationships than attend face-to-face RE. Also couples may prefer being able to complete RE in their homes at their own pace without disclosing information to strangers.

The potential reach of flexible delivery RE is consistent with advocacy for the broader use of flexible delivery to make many psychological services more accessible (Kazdin and Blaze 2011). Moreover, flexible delivery is preferred by many people even when face-to-face psychology services are available (Taylor et al. 2002). A diverse range of information technologies (IT) are being used as a means to flexibly deliver psychological services including mobile (cell) telephones, video-and web-conferencing, Digital Video Discs (DVDs), and the internet (Bennet-Levy et al. 2010). There is now a substantial body of evidence showing that flexible delivery psychological services can be effective. For example, internet treatments for depression (Richards and Richardson 2012) and anxiety (Reger and Gahm 2009) have well established efficacy. However, flexible delivery programs without any professional support tend to have high drop-out rates, and smaller effects, than flexible delivery programs that have some professional contact (Richards and Richardson 2012). Drop out from unsupported flexible delivery psychological services is particularly common in people with low levels of education (Kavanagh and Bennet-Levy 2010).

Consistent with findings for flexible delivery psychology services more generally, a recent meta-analysis of flexible delivery RE found there was a moderate effect size gain in relationship satisfaction when programs included some contact and support with a professional (McAllister et al. 2013). However, entirely self-directed RE programs with no professional contact had no detectable benefits. This might mean that entirely self-directed RE is never effective, or that only some couples benefit from self-directed $\mathrm{RE}$ and that many could benefit from flexible RE with some professional support.

In summary, RE has great potential to enhance couple relationships, but its potential impact is compromised by its modest reach. Flexible delivery RE is promising as a means to reduce identified barriers to RE attendance, but whether high risk couples will engage with and complete flexible delivery RE of sufficient intensity to help their relationship is unclear. The current study is a large scale efficacy trial, involving online recruitment and flexible delivery of RE. The aim was to test the engagement of couples with different intensities of flexible delivery RE, and whether this engagement was influenced by risk. Specifically we hypothesized that attractants to couples engaging with and completing flexible delivery RE would be higher valuing of marriage, higher relationship commitment, greater religiosity, and more relationship problems. We also hypothesized that the following would be barriers to couples engaging with and completing flexible delivery RE: low formal education, and increasing time and effort needed to complete the RE. Given the mixed findings on whether risk influences RE attendance, but given the importance of attracting and retaining high risk couples, we did not make specific predictions but tested whether the following risk factors for future relationship dissatisfaction influenced RE engagement and attendance: divorce in the family of origin, violence in the family of origin, being in a stepfamily, or psychological distress in either spouse. 


\section{Method}

Participants

All couples were recruited to this study through the internet over a twenty-four month period during the years of 2009-2011. Ads were placed on Facebook and Google seeking couples who wanted to receive RE free of cost and told that they would receive gift certificates of twenty dollars upon completion of their RE program. Nine hundred and thirty-four couples responded to the advertisements and qualified for the study by answering screening questions that indicated they were either engaged, living together, or married for $<5$ years, were not violent in their relationship, were not in extreme relationship distress, and were not currently in psychological treatment for individual or couple problems. Both members of the dyad had to agree to participate in the study. These couples then completed an extensive relationship assessment, the RELATE (Busby et al. 2001), from which the demographic information and the pretest measures were obtained. The sample was clearly a national sample with $29 \%$ of the sample being from the East Coast, $14 \%$ coming from the South, $15 \%$ coming from the Midwest, $12 \%$ from the Plains States, $14 \%$ from the Mountain West, and the remaining $16 \%$ from the West.

The sample consisted primarily of Caucasian individuals (76\%), with smaller percentages of African Americans (8\%), Latinos (5\%), Asians (3\%) and "other" (8\%). In terms of education, $52 \%$ had some college and $39 \%$ had completed a Bachelor's degree or higher qualification. On religious affiliation, $31 \%$ of the sample was Protestant, $17 \%$ Catholic, $12 \%$ Latter Day Saints (Mormons), $2 \%$ Jewish, $17 \%$ other, and $21 \%$ had no religious affiliation. The average age of the sample was $27.22(S D=7.25)$. Thirty seven percent of the sample was married, $50 \%$ were cohabiting, and $13 \%$ were engaged but not cohabiting. Of those who were married, $86 \%$ were in their first marriage, and the remaining $14 \%$ were remarried. Eleven percent of the sample had been in a relationship for less than a year, $47 \%$ of the sample for $1-2$ years, and $42 \%$ of the sample for 3-5 years.

After approximately 12 weeks, a period long-enough to comfortably complete all of the treatment conditions, couples were given a longitudinal version of RELATE (RELATE-L) that only included the variables that might change across time. The couples were then reassessed with RELATE-L 1 year later.

\section{Procedures}

Upon completion of the screening instrument couples were directed to the RELATE online assessment (Busby et al.
2001), which is a $300+$ items questionnaire based on the developmental contextual theory (Holman and Associates 2001). Both partners individually answered questions about their personality and relationship histories, family-of-origin experiences, couple satisfaction, communication, and dynamics and other details such as demographics. This instrument has been used extensively in RE programs (e.g. Busby et al. 2007; Halford et al. 2010) as both an outcome measure and as a focus of intervention.

After completing RELATE couples were randomly assigned to one of four treatment conditions. The first condition was the Book (BK) condition in which couples received a copy of the book The Five Love Languages (Chapman 1995). This book was used as a type of control condition as it is a popular book but not one that has received empirical support. The second condition was the RELATE (REL) condition where couples received a 13 page printable RELATE Report that summarizes in a series of graphs with explanatory text the couple's relationship strengths and challenges (for an example report, see: www. Relate-Institute.org). A facilitator then contacted the couple by phone and spent $30-45$ min going over the report with them and helping them make plans on how they could strengthen their relationship. The third condition was the Couple CARE condition adapted to be provided over email (CCE). After couples received feedback about their RELATE report over email, couples received the Couple CARE program which consisted of six units that focused on helping individuals implement self-change, improve communication, learn to be more intimate and caring, learn to more effectively manage differences, improve sexual intimacy, and plan for the future. Couples received a workbook with information and written exercises they were to complete along with a DVD that illustrated the principles from each of the sessions which they watched prior to doing the exercises in their own workbooks. A facilitator then contacted the couple over email after each unit was completed to help them understand and implement the principles they had studied. The fourth condition was Couple CARE (CCP) which was the same program as the CCE condition except the facilitator contacted the couple to go over their RELATE report after each session by telephone instead of by email. Each call lasted approximately $45 \mathrm{~min}$ for each unit.

During the first 6 months of the study even numbers were randomly assigned to each condition, but as the study progressed it became clear that couples were dropping out of the two Couple CARE conditions, which each required completion of six units of self-directed learning materials, at a much higher rate than the other two conditions. Therefore, from that point forward two couples were assigned to these conditions for every one couple that was assigned to the other conditions. This change in random 
assignment created uneven numbers in the different conditions. However, analysis of the groups on the pretest data indicated that the random assignment was effective in creating groups of couples that were not significantly different at pretest on any of the outcomes described in the measures section.

Once couples were randomly assigned to condition, they were advised of the condition and reminded that they would receive their incentive payment after they completed the post-RE assessment at 12 weeks. Couples in the REL and CCP conditions were informed that they would be contacted by a facilitator via telephone to discuss their assessment results. Couples in the CCP condition were told they also would be contacted by telephone for review of each of the six unit sessions of Couple CARE. Couples in the CCE condition were told a facilitator would contact them by email to review their RELATE report and to review the six Couple Care units.

\section{Facilitator Training}

There were 19 facilitators in this study. Other than the book condition, all facilitators were trained to deliver each treatment condition and they were randomly assigned to each couple, who were randomly assigned to each condition resulting in relatively equal percentages of couples in each condition for each facilitator. Seventy-nine percent of the facilitators were females and $21 \%$ were males. Fortyeight percent were family therapy students in training while $52 \%$ were undergraduate family life educators. The undergraduate students were all seniors and were interviewed and screened for their maturity and potential to provide RE. The average age of the facilitators was 28 . The therapy students had completed a mean of $170 \mathrm{~h}$ of supervised clinical work.

The facilitators completed $8 \mathrm{~h}$ of training in RELATE interpretation processes including live supervision of roleplays of interpreting RELATE with a couple and were supervised in their interpretation sessions each week. In this live supervision of role-plays part of the training, facilitators were compared in how they interpreted RELATE to increase each facilitator's skills and ability to do accurate interpretations and increase inter-facilitator reliability. The interpretation guidelines were manualized and can be seen on the RELATE website (www.realatein stitute.com). The supervision of the facilitators was done weekly in a 2-h group format session. Each facilitator was asked to present any problems with interpretation or questions about it before doing an interpretation with a couple. Since RELATE interpretation guidelines are simple, clear, and easily learned, intense live supervision of their interpretation sessions was not deemed necessary. However, in some cases, facilitators had individual supervision with the trainer before doing an interpretation session if the couple's RELATE results looked complicated or the couple appeared to be in some distress in their relationship. Facilitators also contacted the trainer via email or phone as needed to answer questions about some interpretations before the interpretation session occurred. In some cases, the trainer read the email responses the facilitator planned to use with a couple before they sent the message, and made suggestions to help the facilitator do the interpretation as outlined and practiced in the training module. This type of supervision with RELATE facilitators has shown to be effective in previous research using RELATE (see Larson et al. 2007).

Training in facilitation of the Couple Care program consisted of $11 \mathrm{~h}$ using the Couple Care Educator's Manual (see at: www.couplecareinfo.com.au) followed by weekly supervision as above for RELATE. All facilitators were required to follow the National Council on Family Relations (NCFR) Ethical Guidelines for Family Scientists (NCFR 2009) in consulting with couples. Emphasis was placed on not doing therapy with any couple but rather serving only as a couple relationship educator/facilitator with each couple.

The trainer had 25 years of experience doing couple relationship education and had conducted national training workshops in RELATE interpretation. He was also certified to teach Couple Care and has conducted Couple Care facilitator training workshops. The trainer was a Licensed Marriage and Family Therapist and Certified Family Life Educator and has published over 30 book chapters and journal articles on couple relationship education.

\section{Measures}

\section{RE Engagement}

This was a single item that had two categories, RE dropout and RE completed. Initially we had three levels for this variable, RE dropout, RE partial completion, and $\mathrm{RE}$ completed, but in the preliminary analyses there were no differences on any of the variables in this study between the RE dropouts and the RE partial completion groups so we collapsed these two groups.

\section{RE Effort}

This was a single item measure that rated the four RE programs according to the effort required by the participants. The Book group had a value of 1 as it required no contact with a facilitator and couples simply received a book. The REL group had a value of 2 as this group was required to have one phone session with a facilitator to go over their RELATE results. The CCE group had a value of 
3 as they had to engage in the RELATE interpretive session, read and discuss the Couple CARE lessons, and communicate with a facilitator after each of the six sessions over email. The CCP had a value of a 4 as it required phone conversations of approximately $30-45 \mathrm{~min}$ with the facilitator after completing the readings and assignments of each Couple CARE session. While this measure of effort did distinguish between the amount of time and effort formally connected to participants' RE program as these programs are designed (in terms of the amount of time couples are expected to exert for each type of RE) it could not distinguish between the amount of actual effort some couples might have spent going over materials such as the workbook, DVD, and book, on their own.

\section{Importance of Marriage}

This scale consisted of the mean score of four items evaluating how important marriage was for the couples including items such as "Being married is one of the one or two most important things in life." These questions were answered on a five-point Likert type response scale that ranged from "strongly agree" to "strongly disagree." Cronbach's alpha with this sample for males was .71, and for females was .66.

\section{Relationship Stability}

This scale consisted of the mean score of three items measuring how stable the relationship was with questions such as "How often have you thought your relationship might be in trouble." There were five response choices ranging from "never" to "very often." Items were reverse coded so that a higher score indicated more stability and had a range from 1 to 5 . These items were adapted from earlier work by Booth et al. (1983). Cronbach's alpha with this sample for females was .72, and for males was .74 . Previous studies have shown this scale to have test-retest reliability values between .78 and .86 and to be correlated with other relationship quality measures, and to be valid for use in cross-sectional and longitudinal research (Busby et al. 2001, 2007, 2009).

\section{Relationship Problems}

Is the mean score of ten items that lists common problem areas for couples such as "finances, sexuality, communication, children," etc. Couples are asked to indicate for each of the ten areas how often that area has been a problem for them ranging from "never" to "very often." The range for this scale score was also 1-5. Cronbach's alpha with this sample for females was .72, and for males was .78. Likewise this scale has been used and tested extensively in previous work and had test-rest reliability values between .80 and .87 , has been correlated with other relationship quality measures, and has been used in both cross-sectional and longitudinal research measuring change (Busby et al. 2001, 2007, 2009).

\section{Mental Health}

This was a 14 item measure known as the short version of the Adult Mental Health Measure (Keyes 2005). This measure included questions such as "In the last month how often did you feel happy" that were answered on a sixpoint Likert type scale that ranged from "never" to "every day." The total score was a mean of the 14 items with a range from 1 to 6 . Cronbach's alpha with this sample for females was .91, and for males was .92. This scale has been used to assess mental health rather than disorder, and includes content on the experience of positive emotions, good interpersonal relationships, and a sense of belonging and meaning.

\section{Stepfamily Status}

This was a single dichotomous item where individuals indicated if in their current relationship either partner had children from a previous relationship.

\section{Religiosity}

This was the mean score of a four item scale that assessed each individual's religiosity. It included questions such as how often they prayed, attended church, and spirituality was an important part of their life. Three of the four questions were answered on a five-point Likert type scale ranging from "never" to "very often" whereas the church attendance question have a four point scale ranging from "never" to "weekly." The range on this scale was from 1 to 5. Cronbach's alpha with this sample for males was .90 , and for females was .90. This scale has been used extensively in research were religiosity was an important predictor or control variable in couple research (e.g. Busby et al. 2013).

\section{Education}

A single item for males and females with categories as indicated in the sample section.

\section{Parental Divorce in the Family of Origin}

This was coded separately for the female partner or the male partner $(0=$ no, $1=$ yes $)$. 


\section{Family Violence in the Family of Origin}

The measure of violence consisted of questions evaluating whether the participant was physically or sexually victimized by family members before the age of 18 , and if they were how frequently they were victimized. There were also questions evaluating whether their parents physically hit one another and whether other children in the home were physically or sexually victimized. The questions on the specific types of violence were answered on a five-point Likert scale ranging from "never" to "very often." This was also a mean score with a range from 1 to 5 . These questions were adapted from the Conflict Tactics Scales (Straus 1979). Cronbach's alpha with this sample for females was .82, and for males was .80 . These scales have been used extensively in research on family violence with couples (e.g. Busby et al. 2008).

\section{Results}

Figure 1 shows the flowchart of participation and how couples dropped out at different stages of involvement. Ninety-seven percent of the couples passed the screening questions and were sent to the assessment instrument. Thirty-three percent (934) of the 2,798 couples who started the assessment had both partners complete RELATE. Of the 934 couples who were randomly assigned to one of the 4 RE conditions, 571 (61\%) couples declined to commence their assigned RE while 363 (39\%) started a RE program. Of the 363 couples who commenced RE, 243 (67\%) completed their assigned RE program. We compared the 243 couples who completed RE with the 691 couples who either declined to start, or who dropped out and failed to complete RE.

To answer our research questions we conducted a discriminant analysis. This analysis is particularly well-suited for determining what contributes to membership in a categorical dependent variable. In this instance we were trying to predict, based on the variables previously described, whether individuals would complete their RE experience or would drop out prior to completion.

The overall Wilks' lambda was significant, $\Lambda=.85$, $\chi^{2}=(18, \mathrm{~N}=919)=147.00, p<.001$, indicating that overall the predictors differentiated between the drop-out group and the group that completed their RE experience.

Initially the discriminant analysis computes univariate statistics to see if individuals in the two groups are significantly different from one another on each predictor, this usually indicates which predictors will have a substantial influence on the discriminant functions. Table 1 contains the means and univariate tests for each predictor. On 8 of the 18 variables (44\%) the group that completed the RE program had significantly different means than the group

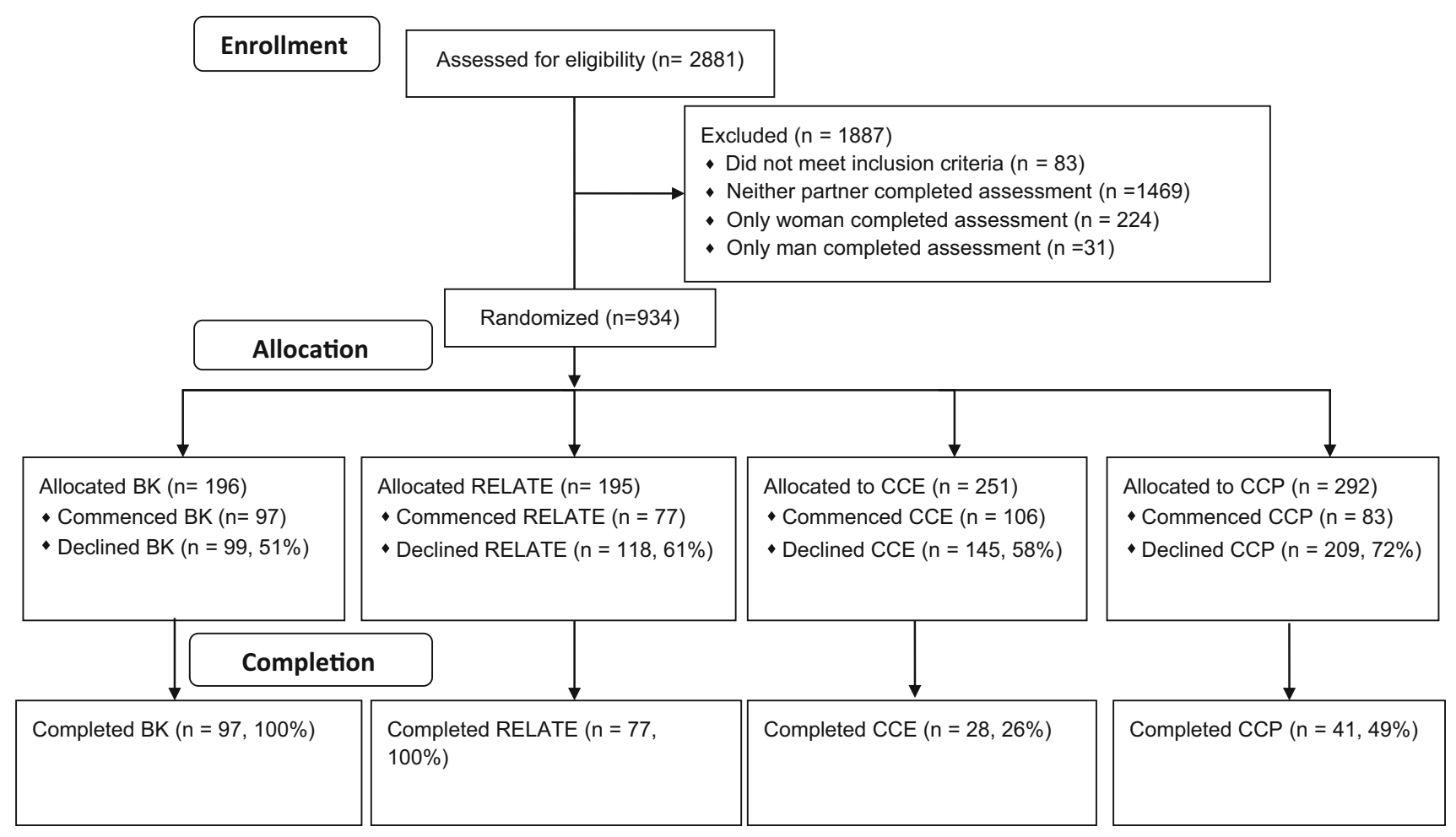

Fig. 1 Participation flow diagram 
Table 1 Univariate statistics for variables predicting $\mathrm{RE}$ completion

\begin{tabular}{|c|c|c|c|c|c|c|}
\hline \multirow[t]{2}{*}{ Variable } & \multicolumn{2}{|c|}{ RE dropout } & \multicolumn{2}{|c|}{ RE completed } & \multirow[t]{2}{*}{$\mathrm{F}$ value } & \multirow[t]{2}{*}{ Sig. level } \\
\hline & Mean & SD & Mean & SD & & \\
\hline RE effort & 2.90 & 1.05 & 2.05 & 1.09 & 112.26 & .000 \\
\hline Importance of marriage $(F)$ & 3.14 & .84 & 3.26 & .86 & 3.77 & .053 \\
\hline Importance of marriage (M) & 3.15 & .85 & 3.37 & .88 & 10.94 & .001 \\
\hline Relationship stability (F) & 4.08 & .73 & 4.20 & .69 & 5.01 & .026 \\
\hline Relationship stability (M) & 4.13 & .71 & 4.25 & .73 & 3.71 & .054 \\
\hline Relationship problems (F) & 3.99 & .54 & 4.06 & .49 & 2.78 & .096 \\
\hline Relationship problems (M) & 3.95 & .58 & 3.97 & .54 & .33 & .561 \\
\hline Mental health (F) & 3.36 & .85 & 3.47 & .79 & 2.91 & .088 \\
\hline Mental health (M) & 3.41 & .88 & 3.42 & .80 & .01 & .989 \\
\hline Stepfamily status & .24 & .43 & .14 & .35 & 10.70 & .001 \\
\hline Religiosity (F) & 3.03 & 1.22 & 3.31 & 1.28 & 8.46 & .004 \\
\hline Religiosity (M) & 2.84 & 1.24 & 3.09 & 1.30 & 7.17 & .008 \\
\hline Education (F) & 5.70 & 1.83 & 5.99 & 1.76 & 4.69 & .031 \\
\hline Education (M) & 5.37 & 1.90 & 5.82 & 1.89 & 9.86 & .002 \\
\hline Parental divorce $(\mathrm{F})$ & .35 & .48 & .31 & .46 & 1.60 & .206 \\
\hline Parental divorce $(\mathrm{M})$ & .31 & .46 & .29 & .46 & .33 & .564 \\
\hline Family violence $(\mathrm{F})$ & 1.29 & .60 & 1.20 & .54 & 3.72 & .054 \\
\hline Family violence (M) & 1.18 & .51 & 1.20 & .51 & .41 & .521 \\
\hline
\end{tabular}

Table 2 Pooled within-groups correlations between discriminating variables and discriminant function (sorted by strength of correlations)

Table 3). The bold results in Table 3 show that the predictors were slightly better, $72 \%$, at classifying those who completed the RE program than those who did not, $68 \%$.

Finally, to assess how well the classification procedure would predict in a new sample, we estimated the percent of cases correctly classified using the leave-one-out technique. This statistical approach is where one case is left out that did not. As is clear from this table, those who completed the RE program were more likely to have been assigned to a low effort RE program, to highly value marriage, to have better relationship stability, higher religiosity, to not be in a stepfamily, and to have more education. There were not significant mean differences on relationship problems, psychological distress and all of the family of origin variables.

The pooled within-groups correlations between the predictors provides some degree of comparison between the relative influence of the predictors for determining group membership. Table 2 contains these statistics and indicates that the most influential variables for predicting who would complete their program were RE effort, importance of marriage for males, stepfamily status, education level of males, and religiosity for both genders. RE effort had a correlation that was approximately 3.2 times are large as the next strongest variable.

When we tried to predict membership in the dropout or completion groups, we were able to correctly classify $69 \%$ of our sample, compared to the $50 \%$ of our sample who would be classified correctly by chance alone (see

\begin{tabular}{ll}
\hline Variables & Correlation \\
\hline RE effort & .832 \\
Importance of marriage (M) & .260 \\
Stepfamily status & .257 \\
Education (M) & .247 \\
Religiosity (F) & .228 \\
Religiosity (M) & .210 \\
Relationship stability (F) & .176 \\
Education (F) & .170 \\
Importance of marriage (F) & .153 \\
Family violence (F) & .152 \\
Relationship stability (M) & .151 \\
Psychological distress (F) & .134 \\
Relationship problems (F) & .131 \\
Parental divorce (F) & .099 \\
Family violence (M) & .050 \\
Relationship problems (M) & .046 \\
Parental divorce (M) & .045 \\
Psychological distress (M) & .001 \\
\hline
\end{tabular}

and classified based on discriminant functions obtained on the remaining cases, and this process is repeated until all cases have been left out once; therefore, the data used for 
Table 3 Participants correctly classified into RE dropout or completion groups

\begin{tabular}{lcll}
\hline Sample & \multicolumn{2}{l}{ Predicted RE group } & \\
\cline { 2 - 4 } & RE dropout (\%) & RE completed (\%) & Total \\
\hline Original & & $214(32)$ & 676 \\
RE dropout count & $462(68)$ & $175(72)$ & 243 \\
RE completed count & $68(28)$ & & \\
Cross-validated & & $223(33)$ & 676 \\
RE dropout count & $453(67)$ & $167(69)$ & 243 \\
RE completed count & $76(31)$ & & \\
\hline
\end{tabular}

classification are not the same as the ones used in formulating the classification statistics (Huberty 1984). With this technique, we were able to estimate more accurately how well the classification functions should predict with a new sample even though we only had one sample. With the leave-one-out technique, we obtained a $68 \%$ correct classification rate as indicated in Table 3 under the crossvalidation section. This indicated that our classification procedure was stable and substantially better than what would be obtained by chance alone.

\section{Discussion}

Determining the factors that might help predict which couples will complete RE programs is of crucial importance. Millions of dollars have been spent during the last decade on RE programs with little information on why certain couples complete their programs while others do not. In this study, which is likely the first study able to use a national campaign for recruitment due to the ability to provide the RE programs over a distance, we were able to test different factors that might contribute to completion rates. First we found while we could attract large numbers of couples who expressed some interest in RE by going to an online site offering free RE, in only $33 \%$ of the cases did both partners complete the online assessment. The findings clearly show that as the type of RE program becomes more demanding in terms of what is asked from couples, and what is provided to couples, they are much more likely to decline to commence or drop out of the RE program. This high attrition was despite offering the programs in flexible delivery mode which involved less effort to attend than the typical in-person group format offered by many RE programs.

As is clear from Fig. 1, the relatively low effort required from the BK and REL groups resulted in high completion rates, whereas the two Couple CARE conditions had much higher dropout rates. Of additional interest from Fig. 1, more couples were willing to start the Couple CARE program, $42 \%$, when they learned they were in the email condition that did not require telephone calls, as compared to the telephone protocol where only $28 \%$ started their program. The use of email as a form of contact and an exclusive form of education delivery is unique to this study and is a format that should receive much more attention and energy in the future. However, it appears that phone contact helped couples feel more invested and complete their program as the CCP group had a completion percentage of $49 \%$ of those who started the program as compared to a completion percentage of only $26 \%$ for the CCE group (the email condition). These results are important information for future RE efforts. It is far easier to get couples interested in reading a book (although we do not know how many read any or all of the book but at least they continued to respond to contact at the 12 week followup) or examining results from an assessment measure than it is to engage them in regular sessions. However, couples seem more willing, at least initially, to start a session based RE program over email than by phone, but the phone condition is almost twice as effective in getting couples to complete a program.

These findings speak to several intriguing possibilities for future designers of RE programs. A very short assessment, perhaps 20-40 questions may gather enough information to give couples quick feedback about the need for a longer assessment or a more formal program. This may eliminate the two-thirds loss of participants who dropped out after the screening questionnaire but before both partners completed the $300+$ item RELATE assessment. Additionally, reading materials that can be perused at leisure would seem to be something all couples could benefit from. Finally, couples could be given the option of more contact and more help by either phone or email. This could be tied to specific assessment results or just offered as a general service for them to work on their relationship as desired. It might even be helpful to let couples know that research has shown that phone contact can bring the added benefit of increasing the likelihood that they will complete their program. Creative combinations of all four types of programs to meet the desires and specific needs of each couple would likely be a fruitful approach for future RE programs and research.

Beyond the intensity of the RE program, in this study we found that some couple and individual characteristics influenced RE completion rates. Highly valuing marriage, more education and religiosity, and not being in a stepfamily improved completion rates. These findings match previous research (Blair and Cordova 2009; Doss et al. 2009; Duncan et al. 2007; Halford et al. 2006). If couples do not highly value marriage and are not high on religiosity or educational attainment it would be worth adding additional recruitment and retention efforts to RE programs. 
The stepfamily risk factors are worth noting. It would seem that the known fact that stepfamilies are at higher risk than non-stepfamilies for future relationship difficulties would be a factor that would lead those in stepfamilies to seek RE more often and complete it once they started. Since this is not the case it may be that their experiences with relationship and psychological help during previous difficulties in previous relationships that did not prevent divorce or dissolution has led to the development of pessimistic attitudes regarding intervention. These speculations would be worth exploring in future research as learning how to engage and help stepfamilies should be a high priority.

It was surprising that none of the risk factors we tested, from psychological distress to more relationship problems, had much influence on completion rates. It may be that relational or psychological distress are not nearly as relevant as the investment required by the RE programs and whether individuals already have an educational orientation, as measured by higher levels of educational attainment, and higher levels of valuing marriage.

There are several limitations with the data in this study. First, we do not know anything about the characteristics of the couples who made initial contact but did not complete the pre-RE assessment. Second, we do not know how much use couples made of the RE resources they were provided. For example, we did not collect data on how much the partners read the book provided in that condition, or implemented relationship changes based on RELATE feedback, or how much time they spent with the DVD or workbook from Couple CARE. While these issues suggest that the RE effort variable might have considerable measurement error, based on how much more time and effort is required of couples in the Couple CARE program as compared to the other two conditions, it is likely that we underestimated the influence of RE effort on dropout rates. Future researchers could improve the measurement in this area by gathering from couples after they completed their programs the amount of time in hours or minutes that were spent on the different materials and sessions. Of course when couples drop-out this information cannot be collected so it may still not be possible to predict drop-out rates as well as we would like.

Nevertheless, this is the first study we are aware of that used a national recruitment strategy, as we had initial contact from more than 2,800 couples, with modest cost. It might well be that by reducing barriers to access that might dissuade less motivated couples, we reduced the proportion of couples identified who do engage with traditional effortful forms of RE. In other studies where participants have to make contact with group leaders, perhaps only more motivated couples ever get to initial contact. The more than 900 couples who were randomly assigned to RE groups is a much larger sample than almost all other RE studies. Because so many couples completed a thorough assessment, it was possible to consider a wide variety of variables that might influence completion rates. It is clear from the results in this study that the primary impediment to completing an RE program is the degree of effort and contact that is asked of couples. Although perhaps obvious that when more is asked of couples they drop out more, in light of the fact that many couples had significant relationship needs, and even the most demanding program was something that could be completed in their home for free, it is surprising how difficult it was to get couples to complete six sessions.

There are several important implications from this study for educators and policy makers. The findings in this study clearly indicate that considerable effort needs to be expended to engage and keep couples beyond the normal recruitment practices of a typical RE program. The principles of motivational interviewing (MI) may be helpful in this area (Miller and Rollnick 2012). These principles focus on helping participants resolve ambiguity and tap into their innate desires for better experiences and relationships. Through this interviewing approach participants could be encouraged to set goals and consider RE experiences that might help them achieve their goals. Perhaps training facilitators to use MI principles in their earliest encounters with those showing interest in RE would improve retention rates.

More dramatically, the findings from this study hint that it may be time to reevaluate our entire approach to RE as per the recommendations made by Larson and Halford (2011). In this busy day where practically anything desired can be bought and delivered to our homes with the click of a mouse or tap of the screen, and much more information is available than ever before with little effort, it may be time to meet couples where they are and give them what they want, when they want it, and how they want it. This type of flexibility does not lend itself well to outcome studies and random assignment, but it will likely result in much more participation by larger numbers of couples.

If couples will drop out at rates similar to those found in this study, promoting programs that include expensive group or individual sessions out of the home over many weeks may be wasting resources and will yield little improvements in the general population for those who need and desire RE. As shown in this study, even programs that require all couples to have phone or email sessions over 6 weeks is likely to be a barrier that will not be surmounted by most couples. In contrast it may be time to test programs that engage couples over longer periods of time with short assessments and brief materials with gentle contact by facilitators to build trust. For example, instead of facilitators requiring couples to call in or email after reading material or completing a section of a workbook, a 
facilitator could initially make email contact and offer to help if the couple would like to discuss something about what they read or viewed. The facilitator could suggest that a phone call might help as research has shown that couples who discuss their progress with someone verbally are more successful at completing RE. Facilitators could offer options that the couple selects such as contact weekly, monthly, quarterly, or as needed. In this way couples can dictate the frequency and intensity of their RE to match their lifestyles and relationship needs. There are many options to explore as researchers and educators continue to try to improve the reach and success of RE programs.

Acknowledgments This study was funded by a Grant from the Utah State Marriage Commission.

\section{References}

Bennet-Levy, J., Richards, D. A., Farrand, P., Christensen, H., Griffiths, K. M., Kavanagh, D. J., et al. (Eds.). (2010). Oxford guide to low intensity CBT interventions. Oxford: Oxford University Press.

Blair, J. M., \& Cordova, J. V. (2009). Commitment as a predictor of participation in premarital education. The Family Journal, 17, $118-125$

Booth, A., Johnson, D. R., \& Edwards, J. N. (1983). Measuring marital instability. Journal of Marriage and the Family, 45, 387-394.

Braithwaite, S. R., \& Fincham, F. D. (2009). A randomized clinical trial of a computer based preventive intervention: Replication and extension of ePREP. Journal of Family Psychology, 23(1), 32-38. doi:10.1037/a0014061.

Busby, D. M., Holman, T. B., \& Niehuis, S. (2009). The association between partner- and self enhancement and relationship quality outcomes. Journal of Marriage and Family, 71, 449-464.

Busby, D. M., Holman, T. B., \& Taniguchi, N. (2001). RELATE: Relationship evaluation of the individual, family, cultural, and couple contexts. Family Relations, 50, 308-316.

Busby, D. M., Holman, T. B., \& Walker, E. (2008). Pathways to relationship aggression between adult partners. Family Relations, 57, 72-83.

Busby, D. M., Ivey, D. C., Harris, S. M., \& Ates, C. (2007). Selfdirected, therapist-directed, and assessment-based interventions for premarital couples. Family Relations, 56, 279-290.

Busby, D. M., Willoughby, B. J., \& Carroll, J. S. (2013). Sowing wild oats: Valuable experience or a field full of weeds? Personal Relationships. doi:10.1111/pere.12009.

Casey, L., \& Halford, W. K. (2010). Couples and the silicon chip: Applying technology to couple services. In K. Hahlweg, M. Grawe, \& D. Baucom (Eds.), Enhancing couples: The shape of couple therapy to come (pp. 216-230). Gottingen: Hogrefe.

Chapman, G. D. (1995). The five love languages: How to express heartfelt commitment to your mate. Chicago: Northfield Publishing.

De Maria, R. M. (2005). Distressed couples and marriage education. Family Relations, 54, 242-253.

Doss, B. D., Rhoades, G., Stanley, S., \& Markman, H. J. (2009). Marital therapy, retreats, and books: The who, what, when, and why of relationship help-seeking. Journal of Marital and Family Therapy, 35, 18-29.
Duncan, S. F., Holman, T. B., \& Yang, C. (2007). Factors associated with involvement in marriage preparation programs. Family Relations, 56, 270-278.

Duncan, S. F., Steed, A., \& Needham, C. M. (2009). A comparison evaluation study of web-based and traditional marriage and relationship education. Journal of Couple and Relationship Therapy, 8, 162-180.

Eurostat (2011). Marriage and divorce statistics. http://epp.eurostat. ec.europa.eu/statistics_explained/index.php/Marriage_and_ divorce_statistics. Retrieved November 12, 2012.

Halford, W. K. (2011). Marriage and relationship education: What works and how to provide it. New York: Guilford Press.

Halford, W. K., \& Bodenmann, G. (2013). Effects of relationship education on maintenance of couple relationship satisfaction. Clinical Psychology Review, 33, 512-525.

Halford, W. K., Markman, H. J., \& Stanley, S. M. (2008). Strengthening couple relationships with education: Social policy and public health perspectives. Journal of Family Psychology, 22, 497-505.

Halford, W. K., O'Donnell, C., Lizzio, A. J., \& Wilson, K. L. (2006). Do couples at high risk of relationship problems attend premarriage education? Journal of Family Psychology, 20, 160-163.

Halford, W. K., \& Simons, M. (2005). Couple relationship education in Australia. Family Process, 44, 147-259.

Halford, W. K., Wilson, K., Watson, B., Verner, T., Larson, J., Busby, D., \& Holman, T. (2010). Couple relationship education at home: Does skill training enhance relationship assessment and feedback? Journal of Family Psychology, 24, 188-196.

Hawkins, A. J., Blanchard, V. L., Baldwin, S. A., \& Fawcett, E. B. (2008). Does marriage and relationship education work? A metaanalytic study. Journal of Consulting and Clinical Psychology, $76,723-734$.

Huberty, C. J. (1984). Issues in the use and interpretation of discriminant analysis. Psychological Bulletin, 95(1), 156-171.

Hunt, R., Hof, L., \& DeMaria, R. (1998). Marriage enrichment: Preparation, mentoring, and outreach. Philadelphia: Brunner/ Mazel.

Kavanagh, D. J., \& Bennet-Levy, J. (2010). Facilitating the widespread adoption of low intensity CBT interventions: Adapting interventions to different community contexts. In: J. Bennet-Levy, D. A. Richards, P., Farrand, H. Christensen, K. M. Griffiths, \& D. J. Kavanagh et al. (Eds.) Oxford guide to low intensity CBT interventions (pp. 537). Oxford: Oxford University Press.

Kazdin, A. E., \& Blaze, S. L. (2011). Rebooting psychotherapy research and practice to reduce the burden of mental illness. Perspectives on Psychological Science, 6(10), 21-37.

Keyes, C. L. M. (2005). Mental illness and/or mental health? Investigating axioms of the complete state model of mental health. Journal of Consulting and Clinical Psychology, 73(3), 539-548.

Larson, J. H., \& Halford, W. K. (2011). One size does not fit all: Customizing couple education. In J. Wetchler (Ed.), Handbook of clinical issues in couple therapy (pp. 293-309). Philadelphia: Taylor and Francis.

Larson, J. H., Newell, K., Topham, G., \& Nichols, S. (2002). A review of three comprehensive premarital assessment questionnaires. Journal of Marital and Family Therapy, 28, 233-239.

Larson, J. H., Vatter, R. S., Galbraith, R. C., Holman, T. B., \& Stahmann, R. F. (2007). The relationship evaluation (RELATE) with therapist assisted interpretation: Short-term effects on premarital relationships. Journal of Marital and Family Therapy, 33, 364-374.

Markman, H. J., \& Rhoades, G. K. (2012). Relationship education research: Current status and future directions. Journal of Marital and Family Therapy, 38, 169-200. 
McAllister, S., Duncan, S. F., \& Busby, D. M. (2013). Exploratory analysis of factors associated with participation in self-directed and traditional marriage and relationship education. Marriage and Family Review, 49, 563-584.

Miller, W. R., \& Rollnick, S. (2012). Motivational Interviewing (3rd ed.). NY: Guilford Press.

National Council on Family Relations (NCFR) (2009). Tools for ethical thinking and practice in FLE. Minneapolis.

Petch, J., Halford, W. K., Creedy, D. K., \& Gamble, J. (2012). A randomized controlled trial of a couple relationship and coparenting program (Couple CARE for Parents) for high- and low-risk new parents. Journal of Consulting and Clinical Psychology, 80, 662-673.

Reger, R. A., \& Gahm, G. A. (2009). A meta-analysis of the effects of internet- and computer-based cognitive-behavioral treatments for anxiety. Journal of Clinical Psychology, 65(1), 53-75.

Richards, D., \& Richardson, T. (2012). Computer-based psychological treatments for depression: A systematic review and metaanalysis. Clinical Psychology Review, 32, 329-342.

Roberts, L. C., Morris, M. L. (1998). An evaluation of marketing factors in marriage enrichment program promotion. Family Relations, 47, 37-44.

Silliman, B., \& Schumm, W. R. (1995). Client interests in premarital counselling: A further analysis. Journal of Sex and Marital Therapy, 21(1), 43-56.

Silliman, B., \& Schumm, W. R. (2004). Adolescents' perceptions of marriage and premarital education. Family Relations, 53(5), 513-520.

Stanley, S. M., Amato, P. R., Johnson, C. A., \& Markman, H. J. (2006). Premarital education, marital quality, and marital stability: Findings from a large, random household survey. Journal of Family Psychology, 20, 117-126.

Straus, M. A. (1979). Measuring intrafamily conflict and violence: The conflict tactics (CT) scales. Journal of Marriage and the Family, 41, 75-88.

Sullivan, K. T. (2001). Understanding the relationship between religiosity and marriage: An investigation of the immediate and longitudinal effects of religiosity on newlywed couples. Journal of Family Psychology, 15, 610-626.

Sullivan, K. T., \& Bradbury, T. N. (1997). Are premarital prevention programs reaching couples at risk for marital dysfunction? Journal of Consulting and Clinical Psychology, 65, 24-30.

Sullivan, K. T., Pasch, L. A., Cornelius, T., \& Cirigliano, E. (2004). Predicting participation in premarital prevention programs: The health belief model and social norms. Family Process, 43, 175-193.

Taylor, C., Jobson, K. O., Winzelberg, A., \& Abascal, L. (2002). The use of the internet to provide evidence-based integrated treatment programs for mental health. Psychiatric Annals, 32, 671-677.

Weston, R., Qu, L., \& Hayes, A. (2012). From form to function: Contemporary choices, changes, and challenges. In P. Noller \& G. C. Karantzas (Eds.), The Wiley-Blackwell handbook of couples and family relationships (pp. 11-24). West Sussex: Willey-Blackwell Publishing.

Wood, R. G., McConnell, S. D., Moore, Q., Clarkwest, A., \& Hsueh, J. (2012). The effects of building strong families: A healthy marriage and relationship skills education program for unmarried parents. Journal of Policy Analysis and management, 31(2), $228-252$. 